\title{
Evaluation of Antimicrobial and Antifungal efficacy of Chitosan as endodontic irrigant against Enterococcus Faecalis and Candida Albicans Biofilm formed on tooth substrate
}

\author{
Pankaj Yadav ${ }^{1}$, Sarika Chaudhary ${ }^{2}$, Rajendra K. Saxena ${ }^{3}$, Sangeeta Talwar ${ }^{4}$, Sudha Yadav ${ }^{5}$ \\ ${ }^{1}$ Senior Resident Associate Professor, Department of Conservative Dentistry and Endodontics, Maulana Azad Institute of Dental \\ Sciences, New Delhi, India \\ ${ }^{2}$ Associate Professor, Department of Conservative Dentistry and Endodontics, Maulana Azad Institute of Dental Sciences, New \\ Delhi, India \\ ${ }^{3}$ Professor Department of Microbiology, University of Delhi South Campus \\ ${ }^{4}$ Professor and HOD Department of Conservative Dentistry and Endodontics, Maulana Azad Institute of Dental Sciences, New \\ Delhi, India \\ ${ }^{5}$ MDS, Senior resident, Department of conservative dentistry and endodontics, Maulana Azad Institute of Dental Sciences, New \\ Delhi, India
}

Correspondence:

Department of Conservative Dentistry and Endodontics

Maulana Azad Institute of Dental Sciences

New Delhi, India

dr.sarika@ymail.com

Yadav P, Chaudhary S, Saxena RK, Talwar S, Yadav S. Evaluation of Antimicrobial and Antifungal efficacy of Chitosan as endodontic irrigant against Enterococcus Faecalis and Candida Albicans Biofilm formed on tooth substrate. J Clin Exp Dent. 2017;9(3):e361-7.

Received: 03/05/2016 http://www.medicinaoral.com/odo/volumenes/v9i3/jcedv9i3p361.pdf

Accepted: 14/10/2016

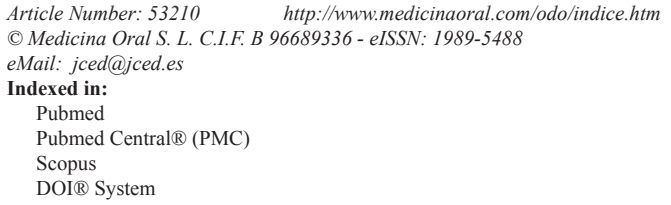

\begin{abstract}
Background: Bacterial biofilms formed on the root canal wall are often difficult to remove. This study aimed to evaluate the cytotoxic effect and antibacterial efficacy of chitosan when used as root canal irrigant against E. Faecalis and Candida albicans biofilm formed on tooth substrate.

Material and Methods: The present study evaluated antibacterial effect of $0.25 \%$ Chitosan, $0.5 \%$ Chitosan, $2 \%$ chlorhexidine and 3\% sodium hypochlorite against Enterococcus faecalis and Candida Albicans. Agar-well diffusion methods, minimal inhibitory concentration tests and biofilm susceptibility assays were used to determine antibacterial activity. Teeth specimens were sectioned to obtain a standardized tooth length of $12 \mathrm{~mm}$. Specimens were inoculated with $10 \mathrm{~mL}$ of the freshly prepared E. Faecalis suspension and Candida albicans for 4 weeks. The specimens were then instrumented with ProTaper rotary files F3 size. After irrigation with test solution, three sterile paper points were placed into one canal, left for $60 \mathrm{~s}$ and transferred to a test tube containing $1 \mathrm{~mL}$ of reduced transport fluid. The number of CFU in $1 \mathrm{~mL}$ was determined.

Results: 3-week biofilm qualitative assay showed complete inhibition of bacterial growth with 3\% Sodium hypochlorite, $2 \%$ Chlorhexidine and Chitosan except saline, which showed presence of bacterial growth. Significant reduction of colony forming units $(\mathrm{CFU}) / \mathrm{mL}$ was observed for the chitosan groups and the antibacterial activity of the chitosan groups was at par with $3 \% \mathrm{NaOCl}$ and $2 \%$ Chlorhexidine. It was observed that the chitosan showed no cytotoxicity at $3 \mathrm{mg} / \mathrm{ml}$ and $10 \%$ cytotoxicity at $6 \mathrm{mg} / \mathrm{ml}$.
\end{abstract}


Conclusions: The use of chitosan as a root canal irrigant might be an alternative considering the various undesirable properties of $\mathrm{NaOCl}$ and chlorhexidine.

Key words: Biofilm, Candida albicans, Chitosan, Cytotoxicity, Enterococcus faecalis.

\section{Introduction}

The persistence and growth of bacteria in root canal system is the main causative factor in pulpal and periradicular lesions (1). The success of the endodontic treatment primarily depends on successful removal of microbes from the infected root canal system (2). Although bacteria are the main microorganisms found in primary endodontic infections, there are some studies which state the presence of fungi in infected root canals (3). Candida albicans and Enterococcus faecalis are considered the most resistant species of fungi and bacteria which are responsible for root canal treatment failures (4). The collagenolytic activity of $C$. albicans promotes colonisation in the root canal as it uses dentin as a nutrient source leading to its high virulence (5).

Chemomechanical preparation plays a major role in disinfection by causing a drastic reduction in the bacterial populations located in the main root canal (6). The choice of an irrigant depends on their effectiveness to act as lubricants during instrumentation, flush debris and smear layer and efficacy on virulent bacteria present in the canal. Variations in chemical formulations of various irrigants might also have different impact with pulp, necrotic tissues and microorganisms (7). Sodium hypochlorite $(\mathrm{NaOCl})$ is the most widely used irrigant due to its antimicrobial and organic tissue dissolving ability but it is toxic to the periapical tissues and weakens dentine by reducing its flexural strength and resilience by making it more susceptible to deformation and possibly fractures (4).

Chlorhexidine has been suggested as efficient alternative to $\mathrm{NaOCl}$. Chlorhexidine gluconate has been widely used in dentistry as an antimicrobial rinse in periodontics and as an effective irrigant in endodontics (8). Chlorhexidine shows broadspectrum antibacterial effect, extended residual activity and a relative absence of toxicity (9). The use of CHX as an endodontic irrigant is restricted because it can discolor teeth and also lacks tissue dissolving ability. Other side effects include loss of taste, burning sensation of the oral mucosa, subjective dryness of the oral cavity and discoloration of the tongue (8).

The search for new alternatives is necessary considering the disadvantages of the available antimicrobial irrigants. Chitosan is a natural polysaccharide which is biocompatible, biodegradable, shows bioadhesion and lacks toxicity (9). Chitosan is a cationic biopolymer that possesses lasting antibacterial properties and low production costs (10). Chitosan is obtained by the deacetylation of chitin, which is found in crab and shrimp shells (11).
To date, none of the study has consistently investigated the effects of chitosan against these microorganisms. So the aim of the study was to evaluate the antibacterial and cytotoxic effect of Chitosan a new alternative when used as root canal irrigant and to compare its action to the commonly used root canal irrigants sodium hypochlorite and chlorhexidine.

\section{Material and Methods}

Candida albicans was cultivated in Sabouraud Dextrose broth and E. faecalis (ATCC 29212) culture was prepared in Mueller-Hinton Broth (MHB) and the turbidity was adjusted to $0.5 \mathrm{McF}$ arland standard to obtain a cell density of $1.5 \times 108$ cells $/ \mathrm{mL}$. Antimicrobial activity of extracts against $E$. faecalis and $C$. albicans was evaluated using agar diffusion, microdilution and biofilm susceptibility tests.

-Test solutions preparation

For preparation of the $0.25 \%$ and $0.5 \%$ chitosan (Mahtani Chitosan Pvt. Ltd Veraval, India) solution, $0.25 \mathrm{~g}$ and $0.5 \mathrm{~g}$ of chitosan was diluted in $100 \mathrm{~mL}$ of $1 \%$ acetic acid and the mixture was stirred for $2 \mathrm{~h}$ using a magnetic stirrer until obtaining crystalline homogeneous solutions with $3.2 \mathrm{pH}$.

-Antibacterial Sensitivity

Well diffusion method was used for the qualitative assay of Antibacterial Activity of the samples. The bacterial strain E. faecalis MTTCC 9221 and Yeast strain Candida albicans were used in the present study. The broth cultures were swabbed on sterile Mueller-Hinton agar plates using sterile swabs. The wells per plate were cut into agar plates with the help of sterile cork-borer and $100 \mu \mathrm{l}$ of test samples $(0.25 \%$ Chitosan, $0.5 \%$ chitosan, 2\% Chlorhexidine, 3\% Sodium Hypochlorite and Saline) were added to the wells respectively. The plates were incubated at $37^{\circ} \mathrm{C}$ for $24 \mathrm{~h}$. The antimicrobial activity was evaluated by measuring the diameter of inhibition zone. All procedures were carried out in triplicate in a laminar flow chamber under aseptic conditions.

$-\mathrm{IC}_{50}$ and MIC determination

The inhibitory concentration $50 \%$ and minimum inhibitory concentration (MIC) of the Chitosan were determined by the tube dilution method. Double dilution was made from a higher dilution $5 \mathrm{mg} / \mathrm{mL}$ to a lower dilution in a series of test tubes. Each tube was inoculated with bacterial suspensions and incubated at $37^{\circ} \mathrm{C}$ for eight hours. The MIC was regarded as the lowest concentration in the series of dilutions, which did not permit the growth of the susceptible bacteria. The antibacterial 
activity of Chitosan was determined by the CFU assay. Briefly, the two potential pathogenic cultures, E. faecalis MTTCC 9221 and Candida albicans (evaluated on the basis of agar diffusion method) were grown to mid-log phase (A600, 0.8) (Fig. 1). $5 \mathrm{ml}$ of bacterial culture were incubated at $37^{\circ} \mathrm{C}$ with different concentrations of Chitosan $(0.5$ to $5 \mathrm{mg} / \mathrm{ml})$, and aliquots of the assay mixture were incubated for 4 hours. Then the chitosan samples inoculated with test cultures were serially diluted with $10 \mathrm{mM}$ phosphate buffer saline (pH 7.4) and $150 \mu \mathrm{l}$ of each was plated on nutrient agar plates and incubated at $37^{\circ} \mathrm{C}$ overnight. $2 \%$ Chlorhexidine and $3 \%$ Sodium Hypochlorite was used as +ve control and double distilled water (DDW) was used as negative control. The test solutions were tested in duplicate utilizing the first bacterial magnification.
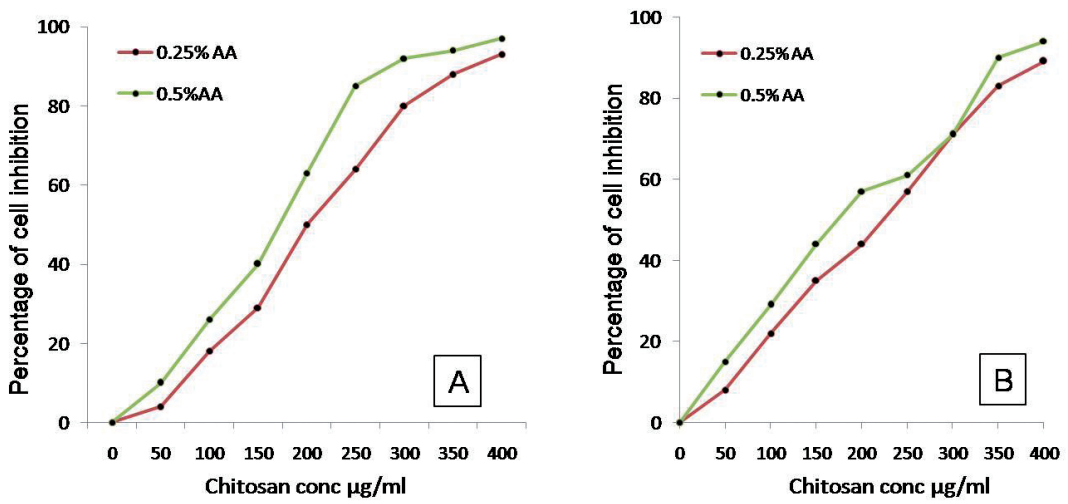

Fig. 1. A) and B) show the percentage of cell inhibition by chitosan for E. faecalis and C. albicans.

\section{-Cytotoxicity assay}

Centrifugation of fresh blood was done, plasma abstracted and packed cell volume of red blood corpuscles was obtained. Red blood corpuscles were washed with saline and centrifuged an abundance of times to abstract white cells and any traces of plasma. $1 \mathrm{ml}$ of packed cell was added to $4 \mathrm{ml}$ of saline to increase the volume of blood to $5 \mathrm{ml}$. A total volume of $100 \mu \mathrm{l}$ of this diluted red blood corpuscles was added to 18 test tubes with six test tubes in each group.

For all the three (Chitosan, Chlorhexidine and hypochlorite) groups, the first test tube was kept as a control in which no irrigant was added. In the second test tube 10 $\mu \mathrm{l}$ of the irrigant was integrated. $20 \mu \mathrm{l}$ was integrated to the third test tube, $30 \mu \mathrm{l}$ to the fourth test tube, $40 \mu \mathrm{l}$ to the fifth test tube and $50 \mu \mathrm{l}$ to the test tube. After an incubation time of $3 \mathrm{~min}$, hemoglobin percentage after hemolysis of red blood corpuscles was noted utilizing an automated hemoanalyzer (ABX Micros 60, HORIBA ABX, Japan). The hemoanalyzer quantified the intracellular hemoglobin content of the remaining red blood corpuscles after hemolysis. For all the three groups, the experiment was reiterated 3 times and the mean value was taken.

-Grouping and assessment protocol

The samples were randomly divided into five experimental groups with 10 samples each for $E$. faecalis and Candida and irrigated with $1 \mathrm{ml}$ of each irrigant for 10 $\min$.

GroupA: $0.25 \%$ Chitosan (pH 3.2)

Group B: 0.5\% Chitosan (pH 3.2)

Group C: $2 \%$ Chlorhexidine

Group D: 3\% Sodium Hypochlorite

Group E: Saline

-Biofilm formation on the root canal

Single-rooted human mandibular premolars with fully formed apices were used in this study. The teeth were cleaned of superficial debris, calculus and tissue tags and stored in normal saline to avert dehydration afore use. Teeth were radiographed to corroborate the presence of a single patent canal. The tooth specimens were sectioned below the cementoenamel junction with a diamond disc to obtain a standardized tooth length of $12 \mathrm{~mm}$ for uniform specimen. The roots were rinsed with distilled water and sterilized in an autoclave at $121^{\circ} \mathrm{C}$ for $20 \mathrm{~min}$. After sterilization, the specimens were incubated in BHI for $24 \mathrm{~h}$ at $37^{\circ} \mathrm{C}$ to confirm that there was no bacterial contamination. Specimens were inoculated with $10 \mathrm{~mL}$ of the freshly prepared $E$. faecalis and Candida albicans suspension and incubated aerobically in a glass test tube at $37^{\circ} \mathrm{C}$ for 4 weeks to allow biofilm formation. The medium was refreshed every 3 days. Random sampling and gram staining confirmed the viability and purity of the $E$. faecalis culture. After four weeks, five specimens were randomly selected and visualized by scanning electron microscopy (SEM) to confirm the formation of the $E$. faecalis biofilms.

-Bacterial quantification

Specimens from E. faecalis and Candida albicans group were treated according to the type of irrigant used during 
instrumentation. All procedures were performed under aseptic conditions. The root canals were negotiated and instrumented to a size $10 \mathrm{~K}$ file (Dentsply Maillefer) without irrigation. The specimens were instrumented with ProTaper rotary files (Dentsply Maillefer) using a crowndown technique, and the canals were enlarged to an F3 ProTaper rotary file using the sequence recommended by the manufacturer. During instrumentation, the canals were irrigated with $1 \mathrm{~mL}$ of the relevant irrigating solution for $10 \mathrm{~min}$ between each instrument change. The solutions were introduced into the canals using a 27 -gauge needle. After irrigation, three sterile paper points were placed into one canal, left for $60 \mathrm{~s}$ and transferred to a test tube containing $1 \mathrm{~mL}$ of reduced transport fluid.

Samples were vortexed for $10 \mathrm{~s}$ and 10 -fold diluted. Aliquots $(0.1 \mathrm{~mL})$ of samples were plated onto BHI agar plates and incubated at $37^{\circ} \mathrm{C}$ for $48 \mathrm{~h}$. The number of CFU in $1 \mathrm{~mL}$ was determined. E. faecalis colony counts were transformed to $\log 10$ values to normalize the data. -SEM observations

The specimens were dried, mounted on metallic stubs, gold sputtered and evaluated by SEM ((JSM5410; JEOL, Tokyo, Japan) micrographs with X1000 and X5000 magnifications (Fig. 2A-D). Two diametrically opposed grooves were made in the teeth utilizing metallic discs under cooling and a bi-bevel chisel was habituated to split the teeth in half lengthwise. The hemisected side with fewer irregularities, which best represented the total root canal length, was selected. These areas were utilized for the SEM analysis by the specialist.

-Statistical analysis

Statistical analysis was performed by using SPSS version 11.5. Along with descriptive analysis, one-way analysis of variance (ANOVA) with Tukey's post hoc testing was done to evaluate the overall significance of $\mathrm{CFU} / \mathrm{mL}$ between and within the different test groups for both E. Fecalis and C. albicans. $P<0.05$ (95\% confidence level) was considered statistically significant.

\section{Results}

\section{-Agar diffusion test}

The test irrigants showed large zones of inhibition against E. faecalis and Candida albicans in the agar diffusion test. Saline showed no antibacterial activity. Inhibitory effects were dependent on concentrations and ranked from the strongest to the weakest solutions as follows for $E$ faecalis: $2 \%$ Chlorhexidine, $3 \% \mathrm{NaOCl}$ and Chitosan. The means of the diameters of the zones of inhibition are shown in table 1 . The size of the zone of inhibition between $\mathrm{NaOCl}$ and $\mathrm{CHX}$ was not statistically different $(p>0.05)$ (Table 1).

-Microdilution test

The minimum inhibitory concentration of chitosan on E. faecalis growth in test tubes was found to be $4.5 \mathrm{mg} /$ $\mathrm{ml}$. Thereafter, a $0.5 \%$ and $0.25 \%$ solution of Chitosan
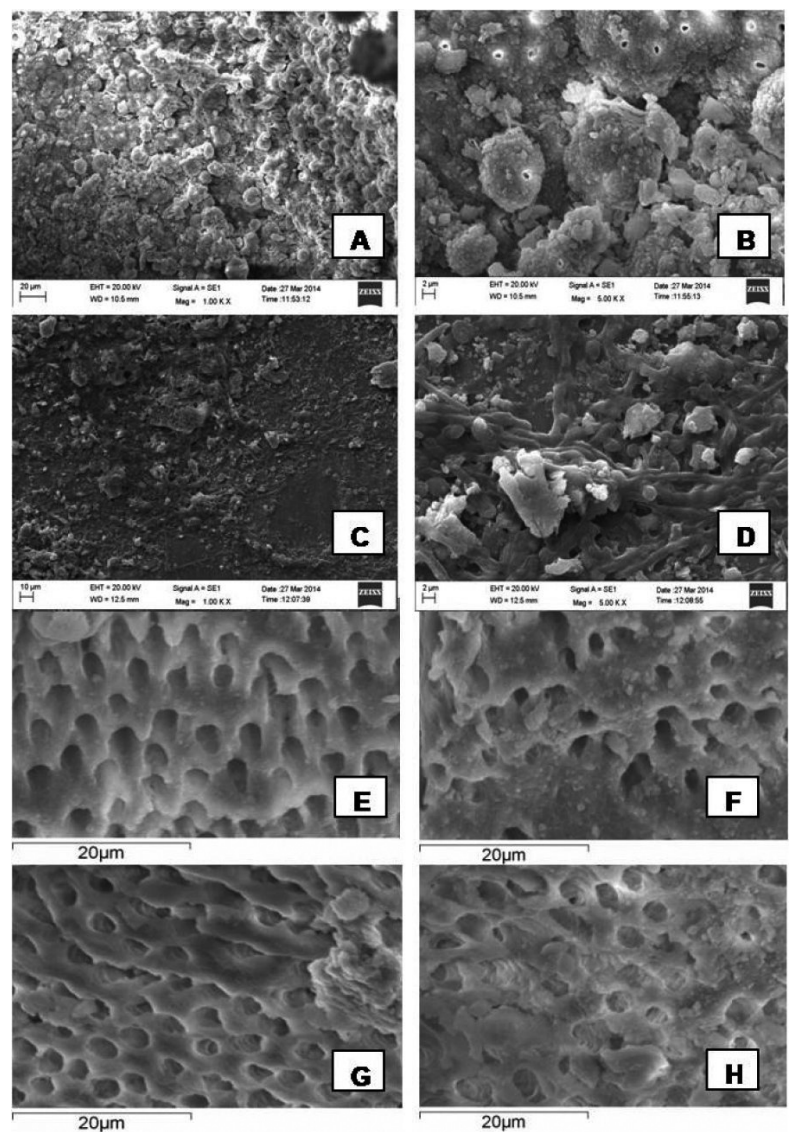

Fig. 2. Photomicrograph of root canals contaminated with E. faecalis and C. albicans. A) E. faecalis $1000 \mathrm{X}$; B) E. faecalis 5000X; C) C. albicans 1000X; D) C. albicans 5000X. E-H) shows SEM images of the inhibition of $E$. faecalis biofilm formation (residual activity) with final irrigation regimens on teeth samples: E) $3 \% \mathrm{NaOCl}$; F ) $2 \%$ Chlorhexidine; G) $0.5 \%$ Chitosan and H) $0.25 \%$ Chitosan .

diluted in $1 \%$ acetic acid was used in comparison with the other treatments.

-Biofilm susceptibility assay

The saline group had the highest mean bacterial count of $67.30 \mathrm{CFU} / \mathrm{ml}$ for E. faecalis (Fig. 3A). For each of the test medications there was a significant decrease in bacteria compared with the saline group. For C. albicans $3 \%$ sodium hypochlorite produced the lowest bacterial counts of any of the test medications (Fig. 3B). The antimicrobial effects of the test irrigants were ranked from strongest to weakest as follows: $3 \% \mathrm{NaOCl}, 2 \% \mathrm{CHX}$ and $0.5 \%$ Chitosan followed by $0.25 \%$ Chitosan and saline.

-Cytotoxicity assay

It was observed that the chitosan showed no cytotoxicity at $3 \mathrm{mg} / \mathrm{ml}$ and $10 \%$ cytotoxicity at $6 \mathrm{mg} / \mathrm{ml}$. The $2 \%$ chlorhexidine showed no cytotoxicity at $10 \%$ conc, $3 \%$ sodium hypochlorite was $72 \%$ cytotoxic at $10 \%$ conc. 
Table 1. Antimicrobial activity and zone of inhibition.

\begin{tabular}{|c|c|c|c|c|c|c|c|}
\hline \multirow[t]{2}{*}{ Test solution } & \multicolumn{2}{|c|}{ Zone of inhibition } & \multicolumn{2}{|c|}{ IC50 } & \multicolumn{2}{|c|}{$\begin{array}{c}\text { Minimum inhibitory } \\
\text { concentration }\end{array}$} & \multirow[t]{2}{*}{$P$ value } \\
\hline & E. faecalis & C. albicans & E. faecalis & C. albicans & E. faecalis & C. albicans & \\
\hline Chitosan & $35 \mathrm{~mm}$ & $21 \mathrm{~mm}$ & $\begin{array}{c}2.7 \\
\mathrm{mg} / \mathrm{ml}\end{array}$ & $\begin{array}{c}3.1 \\
\mathrm{mg} / \mathrm{ml}\end{array}$ & $\begin{array}{c}4.5 \\
\mathrm{mg} / \mathrm{ml}\end{array}$ & $\begin{array}{c}5.0 \\
\mathrm{mg} / \mathrm{ml}\end{array}$ & 0.036 \\
\hline $\begin{array}{l}2 \% \\
\text { chlorhexidine }\end{array}$ & $37 \mathrm{~mm}$ & $29 \mathrm{~mm}$ & $1.98 \mathrm{mg} / \mathrm{ml}$ & $2.42 \mathrm{mg} / \mathrm{ml}$ & $\begin{array}{c}3.3 \\
\mathrm{mg} / \mathrm{ml}\end{array}$ & $4.14 \mathrm{mg} / \mathrm{ml}$ & 0.02 \\
\hline $\begin{array}{l}\text { 3\% sodium } \\
\text { hypochlorite }\end{array}$ & $34 \mathrm{~mm}$ & $35 \mathrm{~mm}$ & $0.97 \mathrm{mg} / \mathrm{ml}$ & $1.02 \mathrm{mg} / \mathrm{ml}$ & $1.4 \mathrm{mg} / \mathrm{ml}$ & $1.62 \mathrm{mg} / \mathrm{ml}$ & 0.041 \\
\hline
\end{tabular}

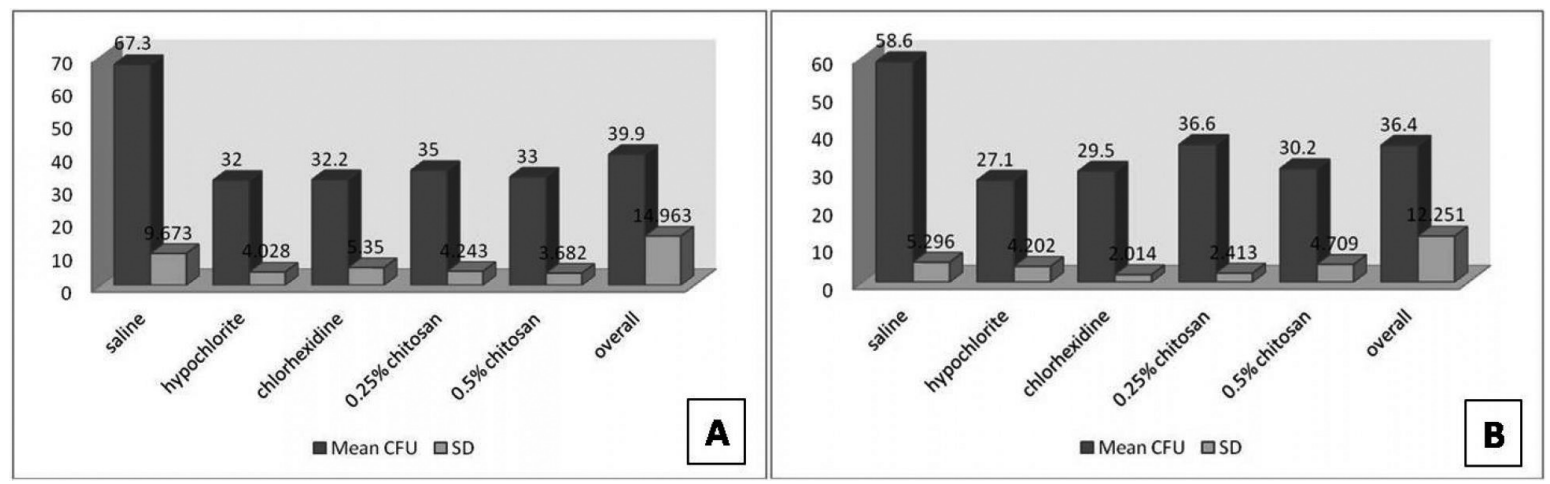

Fig. 3. A) and B) shows Antibacterial activity of Chitosan, Chlorhexidine and Hypochlorite against E. faecalis and C. albicans respectively.

\section{Discussion}

E. faecalis is a facultative microbe that is nonfastidious, easy-to-grow, ability to form monospecies biofilms and progressively and rapidly colonizes tubules. E. faecalis is about nine times more likely to be present in teeth with primary infections that has been root canal treated (12). E. faecalis possess different virulence factors that avail their adhesion to host cells and extracellular matrix, which in turn facilitates tissue incursion, causes immunomodulation and engenders toxin mediated damage (14). Various virulence factors associated with E.faecalis may compete with other microorganisms and resist nutritional deprivation in treated canals (14). It exhibits strong adhesion to collagen (15) and display resistance to chemomechanical preparation (16). It can also survive in a quiescent phase with low metabolic activity for a long period of time (17). Three weeks old E. faecalis biofilm on dentinal canal was preferred in the present study to replicate their usual endodontic significance (18). Longer incubation times may result in a biofilm which is difficult to remove and may influence its susceptibility to disintegration (19).

The root canals of teeth with pulp necrosis, especially those with persistent endodontic infections harbour most commonly the $C$. albicans fungal species. C. albicans forms biofilm as it also has ability to colonize dentinal walls and penetrate into tubules (20).

The choice of culture media in the present study was Sabouraud Dextrose broth and Mueller-Hinton Broth, as these media are readily available and commonly used for $C$. albicans and E. faecalis. In our study to determine the antimicrobial efficacy of the test irrigants agar diffusion test was used. Agar diffusion test is an accepted and standardized method making it reproducible, simple to perform and relatively inexpensive (21).

The utilization of chitosan is justified as alternative option of an irrigating agent with antimicrobial potency. Chitosan's antibacterial nature is due to the interaction between positively charged chitosan and a negatively charged bacterial cell which transmutes the bacterial cell permeability, leading to the leakage of intercellular components and cell death (22). Chitosan binds to DNA and inhibits mRNA synthesis by penetrating toward the nuclei of microorganisms and interfering with the synthesis of mRNA and proteins (22).

Sodium hypochlorite has high surface tension averts di- 
rect contact of the irrigant with the dentinal walls of the anatomical complexities (23). The use of sodium hypochlorite has risk of extrusion into periapical tissues causing inflammation, ecchymoses, hematoma and sometimes even necrosis and paresthesia (24). Chlorhexidine is an efficacious endodontic irrigant due to its antimicrobial activity against Gram-positive and Gram-negative organisms (4).

$3 \% \mathrm{NaOCl}, 2 \% \mathrm{CHX}$ and $.25 \% \& .5 \%$ chitosan were the antimicrobial agents selected in this study to test their efficacy. Numerous studies have evaluated the antimicrobial effects of $\mathrm{NaOCl}$ and $\mathrm{CHX}$ in endodontic treatment $(4,25,26) . \mathrm{NaOCl}$ and chitosan successfully removed and disintegrated the biofilm formed on the surface of the root canal (Figs. 2E,G,H) whereas CHX was found to be less effective on biofilm (Fig. 2F). The present study used SEM as an analyzing tool to assess the formation and the response to the various antimicrobial substances on biofilm. The saline group was the least effective irrigating solution.

The results clearly demonstrated that the action of test irrigants could reduce the number of bacterial cells from the root canal. Bacterial reduction was significantly superior when $\mathrm{NaOCl}$ was used as irrigant. In addition to the mechanical effects, $\mathrm{NaOCl}$ possesses chemical effects that help in the elimination of bacteria from the root canals. The present study demonstrates the antibacterial efficacy of chitosan almost equivalent to $3 \%$ $\mathrm{NaOCl}$, which may well be replaced by this potential animal extract as endodontic irrigant to overcome the deleterious effects of the conventional irrigants $(\mathrm{NaOCl}$ and chlorhexidine) on dentine. $\mathrm{NaOCl}$ is known to be cytotoxic to tissues and a need for replacement with a more biocompatible irrigant is necessitated.

\section{Conclusions}

Under the limitations of this study, it was concluded that:

1. The antibacterial activity of the chitosan groups was at par with $3 \% \mathrm{NaOCl}$ and $2 \%$ Chlorhexidine.

2. It was observed that the chitosan showed no cytotoxicity at $3 \mathrm{mg} / \mathrm{ml}$. The $2 \%$ chlorhexidine showed no cytotoxicity at $10 \%$ conc, $3 \%$ sodium hypochlorite was $72 \%$ cytotoxic at $10 \%$ conc.

3. The use of chitosan as a root canal irrigant might be an alternative considering the various undesirable properties of $\mathrm{NaOCl}$ and chlorhexidine.

\section{References}

1. Kakehashi S, Stanley HR, Fitzgerald RJ. The Effects of Surgical Exposures of Dental Pulps in Germ-Free and Conventional Laboratory Rats. Oral Surgery, Oral Medicine, Oral Pathology, Oral Radiology, and Endodontics. 1965;20:340-9.

2. Siqueira JF Jr, Rocas IN. Clinical implications and microbiology of bacterial persistence after treatment procedures. J Endod. 2008;34:1291-301.
3. Siqueira JF Jr, Rocas IN. Diversity of endodontic microbiota revisited. J Dent Res. 2009;88:969-81.

4. Wali IE, Eid GEM, Omar WA, ElRafie S. The Antimicrobial Efficacy of Ozonated Water, Chlorhexidine and Sodium Hypochlorite against Single Species Biofilms of Enterococcus faecalis and Candida albicans. Egyptian Journal of Medical Microbiology. 2008;17:419-27. 5. Hagihara Y, Kaminishi H, Cho T, Tanaka M, Kaita H. Degradation of human dentin collagen by an enzyme produced by the yeasts Candida albicans. Arch Oral Biol. 1988;33:617-19.

6. Brito PR, Souza LC, Machado de Oliveira JC, Alves FR, De-Deus $\mathrm{G}$, Lopes HP, et al. Comparison of the effectiveness of three irrigation techniques in reducing intracanal Enterococcus faecalis populations: an in vitro study. J Endod. 2009;35:1422-7.

7. Murray PE, Farber RM, Namerow KN, Kuttler S, Garcia-Godoy F. Evaluation of Morinda citrifolia as an Endodontic Irrigant. J Endod. 2008;34:66 -70.

8. Jeansonne MJ, White RR. A comparison of $2.0 \%$ chlorhexidine gluconate and $5.25 \%$ sodium hypochlorite as antimicrobial endodontic irrigants. J Endod. 1994;20:276-8.

9. Akncbay H, Senel S, Ay ZY. Application of chitsan gel in the treatment of chronic periodontitis. Journal of Biomedical Materials Research. Part B, Applied Biomaterials. 2007:80:290-6.

10. Shrestha A, Shi Z, Neoh KG, Kishen A. Nanoparticulates for antibiofilm treatment and effect of aging on its antibacterial activity. $\mathrm{J}$ Endod. 2010;36:1030-5.

11. Silva PV, Guedes DFC, Nakadi FV, Pecora JD, Cruz-Filho AM. Chitosan: a new solution for removal of smear layer after root canal instrumentation. International Endodontic Journal. 2013;46:332-8.

12. Rocas IN, Siqueira JF, Santos KRN. Association of Enterococcus faecalis with different forms of periradicular diseases. Journal of Endodontics. 2004;30:315-20.

13. Jett BD, Huycke MM, Gilmore MS. Virulence of Enterococci. Clin Microbiol Rev. 1994;7:462-78.

14. Portenier I, Waltimo TMT, Haapasalo M. Enterococcus faecalisthe root canal survivor and 'star' in post-treatment disease. Endodontic Topics. 2003;6:135-9.

15. Cardoso M, de Oliveira L, Koga-Ito C, Jorge A, dos Campos S. Effectivenes of ozonated water on Candida albicans, Enterococcus faecalis, and endotoxins in root canals. Oral Surg Oral Pathol Oral Radiol Endod. 2008;105:e85-91.

16. Distel JW, Hatton JF, Gillespie MJ. Biofilm Formation in Medicated Root Canals. J Endod. 2002;28:689-93.

17. Sena NT et al. In vitro antimicrobial activity of sodium hypochlorite and chlohexidine against selected single-species biofilms. Int Endod J. 2006;39:878-85.

18. Subbiya A, Mahalakshmi K, Pushpangadan S, Padmavathy K, Vivekanandan P, Sukumaran VG. Antibacterial efficacy of Mangifera indica L. kernel and Ocimum sanctum L. leaves against Enterococcus faecalis dentinal biofi $\mathrm{lm}$. J Conserv Dent. 2013;16:454-7.

19. Kishen A, George S, Kumar R. Enterococcus faecalis-mediated biomineralized biofilm formation on root canal dentine in vitro. J Biomed Mater Res A. 2006;77:406-15.

20. Svensater G, Bergenholtz C. Biofilms in endodontic infections. Endod Topics. 2004;9:27-36.

21. N. V. Ballal, M. Kundabala, K. S. Bhat, S. Acharya, M. Ballal, R. Kumarand PY, et al. Susceptibility of Candida albicans and Enterococcus faecalis to Chitosan, Chlorhexidine gluconate and their combination in vitro. Aust Endod J. 2009;35:29-33.

22. Sudarshan NR, Hoover DG, Knorr D. Antibacterial action of chitosan. Food Biotechnology. 1992;6:257-72.

23.ZehnderM.Rootcanalirrigants.JournalofEndodontics.2006;32:38998.

24. Rocas IN, Siqueira JF. Comparison of the In Vivo Antimicrobial Effectiveness of Sodium Hypochlorite and Chlorhexidine Used as Root Canal Irrigants: A Molecular Microbiology Study. J Endod. 2011;37:143-50.

25. Ferraz C, Gomes B, Zaia A, Teixeira F, Souza-Filho F. Comparative study of the antimicrobial efficacy of chlorhexidine gel, chlorhexidine solution and sodium hypochlorite as endodontic irrigants. Braz Dent J. 2007;18:294-8. 
26. Dunavant TR, Regan JD, Glickman GN, Solomon ES, Honeyman AL. Comparative evaluation of endodontic irrigants against Enterococcus faecalis biofilms. J Endod. 2006;32:527-31.

\section{Acknowledgments}

The authors gratefully acknowledge Richi V Mahajan and Priyanka Tripathi, Senior Research Associate, Department of Microbiology, University of Delhi South Campus for their valuable comments and guidance all through the study.

\section{Conflict of Interest}

The authors have declared that no conflict of interest exist. 